\title{
The antitumor efficacy of a novel adenovirus-mediated anti-p21Ras single chain fragment variable antibody on human cancers in vitro and in vivo
}

\author{
JU-LUN YANG $^{1,2}$, XIN-YAN PAN $^{1}$, WEN-XING ZHAO ${ }^{1}$, QI-CHAN HU ${ }^{2}$, \\ FENG DING $^{2}$, QIANG FENG ${ }^{1}$, GUI-YUN LI ${ }^{1}$ and YING LUO ${ }^{3}$ \\ ${ }^{1}$ Department of Pathology, Kunming General Hospital of PLA, Kunming 650032; ${ }^{2}$ Graduate School, \\ Kunming Medical University, Kunming 650500; ${ }^{3}$ Department of Genetics, Medical College, \\ Kunming University of Science and Technology, Kunming 650500, P.R. China
}

Received September 9, 2015; Accepted October 23, 2015

DOI: 10.3892/ijo.2016.3334

\begin{abstract}
Activated ras genes are found in a large number of human tumors, and therefore are one of important targets for cancer therapy. This study investigated the antitumor effects of a novel single chain fragment variable antibody $(\mathrm{scFv})$ against ras protein, p21Ras. The anti-p21Ras scFv gene was constructed by phage display library from hybridoma KGHR1, and then subcloned into replication-defective adenovirus vector to obtain recombinant adenovirus KGHV100. Human tumor cell lines with high expression of p21Ras SW480, MDA-MB-231, OVCAR-3, BEL-7402, as well as tumor cell line with low expression of p21Ras, SKOV3, were employed to investigate antitumor effects in vitro and in vivo. Fluorescence microscopy demonstrated that KGHV100 was able to express intracellularly anti-p21Ras scFv antibody in cultured tumor cells and in transplantation tumor cells. MTT, Transwell, colony formation, and flow cytometry analysis showed that KGHV100 led to significant growth arrest in tumor cells with high p21Ras expression, and induced G0/G1 cell cycle arrest in the studied tumor cell lines. In vivo, KGHV100 significantly inhibited tumor growth following intratumoral injection, and the survival rates of the mice were higher than the control group. These results indicate that the adenovirus-mediated intracellular expression of the novel anti-p21Ras scFv exerted strong antitumoral effects, and may be a potential method for therapy of cancers with p21Ras overexpression.
\end{abstract}

\section{Introduction}

Cancer is one of most lethal diseases, and surgical resection or surgery coupled with systemic chemotherapy and radiotherapy

Correspondence to: Dr Ju-Lun Yang, Department of Pathology, Kunming General Hospital of PLA, 212 Daguan Rd., Kunming 650032, P.R. China

E-mail: yangjulun@sina.com

Key words: p21Ras, single chain fragment variable antibody, intracellular antibody, adenovirus, gene therapy are the main approaches currently available for cancer therapy. Despite advanced progress in technologies to diagnose and treat cancers, the global burden of cancer continues to increase greatly (1). Therefore, improved therapeutic approaches are needed for more efficacious control of the malignancy.

Ras genes, one of the earliest oncogenes discovered in human tumors, play an important role in development of many kinds of human tumors (2). Mutations have been identified by which ras can mediate tumorigenesis. Point mutation in the ras gene results in an alteration of a single amino acid in the ras gene product, p21Ras (3), and ras mutations are present in $\sim 30 \%$ of all human cancers (4). Activated Ras and the signaling contributes significantly to several aspects of the malignant phenotype, including the deregulation of tumor-cell growth, programmed cell death and invasiveness, and the ability to induce new blood-vessel formation (5). These results clearly demonstrate that ras oncogenes offer an excellent target for a therapeutic intervention (6). Since Ras signaling depends on the p21Ras precise localization to the inner face of the plasma membrane (4), disturbance and blockade of intracellular Ras signaling may be one of most impressive strategies for ras-driven tumors. Strategies currently being developed mainly target the specific inhibition of Ras farnesylation $(7,8)$ or are based upon neutralizing of ras proteins in cancer cells (9). Among the latter approaches, intracellular expression of single-chain antibody fragment ( $\mathrm{scFv}$ ) has made it possible to neutralize a variety of intracellular harmful molecules $(10,11)$. In previous years, several anti-p21Ras scFv antibodies were reported $(6,12-14)$. However, all of them were derived from mutant p21Ras, and attempts to develop drugs that target mutant Ras proteins have, so far, been unsuccessful (15-17).

Besides mutation, overexpression of wild-type p21Ras is also one of the major cause of cancer development including colon, pancreas, prostate, bladder, breast cancers, and gliomas (18-26). We supposed that the scFv antibody derived from wildtype $\mathrm{p} 21 \mathrm{Ras}$ could have wider range of applications and potent antitumoral effects in ras-driven tumors. However, there was no $\mathrm{scFv}$ antibody against wild-type p21Ras reported. In our previous studies, we prepared an anti- p21Ras scFv using wildtype p21Ras proteins as immunogen. Immunohistochemistry 
demonstrated that this ScFv antibody could bind wild-type and mutated H-p21Ras, K-p21Ras, N-p21Ras and react specifically with human cell lines and primary tumor tissues. In the present study, we investigated whether it could express within cells and inhibit human ras-driven cancer growth in vitro and in vivo.

\section{Materials and methods}

Cell lines. The following human cell lines were employed to observe the antitumor effects of the intracellular scFv antibody against p21Ras. Human colon cancer cell line SW480, human ovarian cancer cell line OVCAR-3, human liver cancer cell line BEL-7402, human ovarian cancer cell line SKOV3, human breast cancer cell line MDA-MB-231 and human embryo lung fibroblast line HLFI were purchased from Shanghai Cell Collection (Shanghai, China). All the cells were cultured in RPMI-1640 medium containing 20\% fetal bovine serum (BSA) at $37^{\circ} \mathrm{C}$ in $5 \% \mathrm{CO}_{2}$, except HLFI cells which were cultured in MEM medium with $10 \%$ BSA.

Western blot analysis. Western blot analysis was used to detect expression of p21Ras in the above-mentioned cell lines. Briefly, cultured cells were harvested when the cell density was $5 \times 10^{5}$ cells/well, lysed in lysis buffer $(50 \mathrm{mM}$ Tris- $\mathrm{HCl}, 150 \mathrm{mM} \mathrm{NaCl}, 1 \%$ Triton X-100, $1 \mathrm{mM}$ EDTA, $0.5 \%$ sodium deoxycholate, $0.1 \% \mathrm{SDS}$ ) with a protease inhibitor cocktail containing phenylmethylsulfonylfluoride (PMSF) for $30 \mathrm{~min}$ to obtain tumor cell total proteins. Equal amounts of cellular proteins were electrophoresed on SDA-PAGE gel and then transferred to PVDF membranes at $4^{\circ} \mathrm{C}$ for $2 \mathrm{~h}$, sealed with $5 \%$ fat-free milk. The membrane was incubated with anti-p21Ras monoclonal antibodies prepared by our laboratory, followed by incubation with goat antimouse IgG/HRP (ZSGB-BIO) at 1:5,000 dilution. Finally, the signals were detected by enhanced chemiluminescence (ECL) according to the manufacturer's recommendations and quantitated by densitometry, with $\beta$-actin serving as an internal control.

Construction of anti-p21Ras scFv antibody gene. pMD18T-KGHR1-scFv plasmids contained anti-p21Ras scFv gene was constructed by our laboratory (unpublished data). Briefly, wild-type H-p21Ras, K-p21Ras and N-p21Ras were expressed in E. coli. BALB/c mice were immunized with H-p21Ras as antigen. Hybridoma producing anti-p21Ras monoclonal antibody KGH-R1 was isolated by screening with wild-type H-p21Ras, K-p21Ras, N-p21Ras. Finally anti-p21Ras scFv gene was generated from the hybridoma cDNA by phage $\mathrm{scFv}$ display techniques.

Preparation of recombinant adenovirus carrying anti-p21Ras $s c F v$ gene. Anti-p21Ras scFv gene (750 bp) was amplified from the plasmids pMD18-T-KGH-R1-scFv by sense primer with restriction enzyme $B g l \mathrm{II}:$ 5'-TTGCGGCCGCAACCGT TTGATT-3' and antisense primer with XhoI: 5'-CCCTCGAG GGCCGCCCGTTTGATT-3'. Then, the PCR was performed by the following parameters: $95^{\circ} \mathrm{C}$ for $5 \mathrm{~min} ; 94^{\circ} \mathrm{C}$ for $30 \mathrm{sec}$; $55^{\circ} \mathrm{C}$ for $40 \mathrm{sec}, 72^{\circ} \mathrm{C}$ for $40 \mathrm{sec}$ x 35 cycles; $72^{\circ} \mathrm{C}$ for $10 \mathrm{~min}$. After $B g l \mathrm{II}$ and $\mathrm{XhoI}$ double digestion, scFv gene was subcloned into the $B g l \mathrm{II}$ and $\mathrm{XhoI}$ sites of the pShuttle-IREShrGFP-1 vector, then identified by PCR amplification using the universal primers on the shuttle vector, pShuttle-F: 5'-CTC ACGGGGATTTCCAAGTC-3'; pShuttle-R: 5'-ATGCAGTCG TCGAGGAATTG-3'. The PCR was performed by the following parameters: $95^{\circ} \mathrm{C}$ for $5 \mathrm{~min}, 94^{\circ} \mathrm{C}$ for $30 \mathrm{sec}, 56^{\circ} \mathrm{C}$ for $40 \mathrm{sec} ; 72^{\circ} \mathrm{C}$ for $40 \mathrm{sec}$ x 35 cycles; $72^{\circ} \mathrm{C}$ for $10 \mathrm{~min}$. After PmeI restriction and CIAP treatment, the pShuttle-IREShrGFP-ScFv underwent linearization and phosphorylation. Then the shuttle plasmid was electro-transformed into competent cells BJ5183-AD-1, which contain adenovirus backbone vector pAdEasy-1 to generate recombinant adenovirus vectors Ad-KGHR1-scFv.

Then recombinant adenovirus vectors were identified by $P a c I$ restriction, and were transfected into HEK293 cells by Lipofectamine 2000 (Invitrogen, USA) to become the packaged recombinant adenovirus, called KGHV100. After cytopathic effects appeared, the cells underwent freeze thawing four times to release the recombinant adenovirus. The recombinant adenovirus KGHV100 was identified by PCR amplification using the universal primers on the shuttle vector to confirm that KGHV100 was successfully constructed. The wild-type adenovirus was excluded through PCR amplification using E1 region as the specific primers. The replicationdeficient adenovirus AdEasy-GFP (Ad-hrGFP) was used as a control, which contained a green fluorescent protein (GFP) gene under the control of a cytomegalovirus promoter. All of the viral particles were prepared by enlargement cultivation and purified by cesium chloride density gradient centrifugation and titered by TCID $_{50}$ method. Adenoviral infection was performed according to the standard protocol (27). All infection experiments were performed at a multiplicity of infection (MOI) of 100 (this work was done in our early experiments) plaque forming units (pfu).

Intracellular expression of anti-p21Ras scFv. MDA-MB-231 cell lines were seeded on slides and cultured in dishes at $37^{\circ} \mathrm{C}$ with $5 \% \mathrm{CO}_{2}$. When $80 \%$ confluent cells formed, recombinant adenovirus KGHV100 was added into cell lines at a multiplicity of infection (MOI) of 100 and cultured continuously for $24 \mathrm{~h}$. Then, the cells on slides were fixed with $4 \%$ paraformaldehyde, and permeabilised with $0.5 \%$ Tween-20. After blocking with BSA, the slides were incubated overnight at $4^{\circ} \mathrm{C}$ with primary anti-Flag Tag rabbit polyclonal antibodies, then incubated for $1 \mathrm{~h}$ at room temperature in the dark with TRITC-conjugated goat anti-rabbit antibody (ZSGB-BIO), washed for $5 \mathrm{~min}$ with PBS and mounted on coverslips. TRITC fluorescence signals were analyzed with an Olympus IV fluorescence confocal microscope (Olympus, Tokyo, Japan).

Colony formation analysis. The SW480, MDA-MB-231, BEL-7402, OVCAR-3 and SKOV3 cell lines were cultured in 24-well plates at $37^{\circ} \mathrm{C}$ with $5 \% \mathrm{CO}_{2}$ and were infected with recombinant adenovirus KGHV100 at a MOI of 100 and were cultured for $24 \mathrm{~h}$. Then, the tumor cells were digested with $0.25 \%$ trypsin and suspended in $20 \%$ FBS. Five hundred cells were cultured in $2.5 \mathrm{ml}$ RPMI-1640 medium containing $20 \%$ fetal bovine serum in the 6 -wells plates for 2-3 weeks. The culture solutions were changed 
when the color changes of the solutions were observed and cell lines growth were terminated when culture clones were observed macroscopically. Cells were washed with PBS and immobilized with methanol for $15 \mathrm{~min}$. Following $1 \%$ Giemsa stain for 10-30 min, the cells were washed with water and dried in air. Colony-forming efficiency was calculated using the formula: Colony-forming efficiency $=$ (numbers of clones/ inoculated cell counts) x $100 \%$.

Transwell invasion assay. Cell invasion ability was assayed in a Transwell cell culture chamber (Corning, USA) according to the manufacturer's protocol (28). Briefly, MDA-MB-231, OVCAR3, SW480, BEL-7402 and SKOV3 cell lines were inoculated into 24 -well plates, when $80 \%$ of confluent cells formed, recombinant adenovirus KGHV100 was added into cell lines at a MOI of 100 and cultured continuously for $24 \mathrm{~h}$ and then cell lines were grow in RPMI-1640 without serum for $12 \mathrm{~h}$. The lower chamber of the Transwell was coated with $50 \mathrm{mg} / 1$ Matrigel (BD, USA), and was filled with $500 \mu$ l RPMI-1640 supplemented with $20 \%$ fetal bovine serum (FBS) as a chemoattractant. Cells $\left(3 \times 10^{4}\right)(\sim 200 \mu 1$ cell suspension) were added into upper layer of the invasion chamber, for static culture for $48 \mathrm{~h}$ at $37^{\circ} \mathrm{C}$. The non-invasive cells on the upper surface of the Matrigel were removed with a cotton swab. The lower changer cells of the microwells were fixed with $95 \%$ ethanol, stained with hematoxylin, then washed with pure ethanol and distilled water, separately, and dried at room conditions. The migrated cells were observed and counted under a microscope by random selection of 10 different microscopical visions.

Cell viability and apoptosis-related gene assay. 3(4,5-Dimethylthiazol-2-yl)-2,5-diphenyltetrazolium bromide (MTT) assay was performed as previously described (29). Briefly, SW480, MDA-MB-231, BEL-7402 and SKOV3 cells were seeded into 96 -well plates at a density of $5 \times 10^{3}$ cells/ well. Twenty-four hours later, the cells were infected with the recombinant $\mathrm{scFv}$-adenovirus $\mathrm{KGHV} 100$ at a MOI of 100, the control blank group was also prepared. At 1,2, 3, 4 and 5 days after infection, $20 \mu \mathrm{l}$ of MTT $(5 \mathrm{mg} / \mathrm{ml})$ was added to each well. After $4 \mathrm{~h}$ of incubation with MTT, DMSO (100 $\mu \mathrm{l} /$ well) was added for $10 \mathrm{~min}$. The optical density (OD) value of each well was measured at $490 \mathrm{~nm}$ by enzyme-linked immunosorbent assay.

For apoptosis-related gene caspase-3 assay, SW480, MDA-MB-231, BEL-7402 and SKOV3 cell were infected with the KGHV100 at a MOI of 100 . After $48 \mathrm{~h}$ total cellular RNA was extracted from cells, $1 \mu \mathrm{g}$ of total RNA was used for reverse transcription with the GoScript ${ }^{\mathrm{TM}}$ Reverse Transcription system (Promega, Beijing, China). Expressions of caspase- 3 was detected by quantitative real-time PCR (qRT-PCR) using primer caspase-3-F and caspase-3-R (Table I). Glyceraldehyde-3-phosphate dehydrogenase (GAPDH) was used as an internal control, with the primers GAPDH-F/GAPDH-R (Table I).

Cell cycle analysis. The tumor cell lines SW480, MDA-MB-231, BEL-7402 and SKOV3 were seeded into the $25-\mathrm{cm}^{2}$ flasks at $37^{\circ} \mathrm{C}$ with $5 \% \mathrm{CO}_{2}$, until $80 \%$ confluent cells formed the cell were infected with KGHV100 at a MOI
Table I. Primers used in qRT-PCR.

\begin{tabular}{ll}
\hline Primer no. & \multicolumn{1}{c}{ Primer sequence } \\
\hline Caspase-3-F & ATCTCCAAGCAATGTTCA \\
Caspase-3-R & ACTACCATATAGCGTGTTC \\
PI3K-F & GTGAAAGACGCCACGACAAT \\
PI3K-R & TCTCCACTGCTGCCTGAAAC \\
PLCE-F & CCAGGGGAGACAGCATCATT \\
PLCE-R & GCATTTTCATTCAGCGACGA \\
RALGDS-F & GCCTCACCTCTTGGTGTTCC \\
RALGDS-R & GTGCTCCTTGCCCTTCTTGT \\
MAPK-F & AAAGGGTCATCATCTCTG \\
MAPK-R & GCTGTTGTCATACTTCTC \\
GAPDH-F & GGACCTGACCTGCCGTCTAG \\
GAPDH-R & GAGTGGGTGTCGCTGTTGAA
\end{tabular}

of 100 . After $48 \mathrm{~h}$, digested with $0.25 \%$ trypsin, cells were harvested. In total, $10^{6}$ cells were washed twice with ice-cold PBS, immobilized overnight with $75 \%$ ethanol, then washed twice again with ice-cold PBS, and stained with $0.5 \mathrm{ml}$ PI (Beckman, USA) for $30 \mathrm{~min}$ in the dark. Samples were processed on a flow cytometer according to the manufacturer's standard protocol. Data were analysed using MultiCycle DNA software. The proliferation index of tumor cells infecting KGHV100 and the adenovirus of Ad-hrGFP were calculated using the following formula: (proliferation index, PI) = $(\mathrm{S}+\mathrm{G} 2 / \mathrm{M}) /(\mathrm{G} 0 / \mathrm{G} 1+\mathrm{S}+\mathrm{G} 2 / \mathrm{M}) \times 100 \%$. All experiments were completed in triplicate.

Quantitative real-time PCR ( $q R T-P C R)$ analysis for downstream genes of ras. BEL-7402 cells were cultured in 6-well plates and were infected with KGHV100 at a MOI of 100, with Ad-hrGFP infected and uninfected cells as control. Forty-eight hours after infection, total cellular RNA was extracted from cells using the Eastep ${ }^{\mathrm{TM}}$ Total RNA Extraction kit (Promega). Total RNA $(1 \mu \mathrm{g})$ was used for reverse transcription with the GoScript ${ }^{\mathrm{TM}}$ Reverse Transcription system (Promega). qRT-PCR was used to detect expression of downstresm genes of ras, MAPK1, PI3K,PLC $\varepsilon$ and RALGDS, using corresponding primers (Table I). Glyceraldehyde-3phosphate dehydrogenase (GAPDH) was used as an internal control, with the primers GAPDH-F/GAPDH-R. A negative control with no template was included for each reaction series. The cycles were as follows: $95^{\circ} \mathrm{C}$ for $10 \mathrm{~min} ; 95^{\circ} \mathrm{C}$ for $10 \mathrm{sec}, 58^{\circ} \mathrm{C}$ for $20 \mathrm{sec}, 72^{\circ} \mathrm{C}$ for $20 \mathrm{sec}$, for $45 \mathrm{cycles}$. The amplification products were separated by $2 \%$ agarose gel electrophoresis and visualized by SYBR Green staining (Bio-Rad, USA). Data were analyzed with Bio-Rad CFX96 Manager software.

In vivo tumor-killing assay. This study was approved by the Ethics Board of Kunming General Hospital, and is in accordance with the Helsinki Declaration of 1975. Animals involved in the study were cared for in accordance with institutional guidelines. BEL-7402, SW480 and SKOV3 


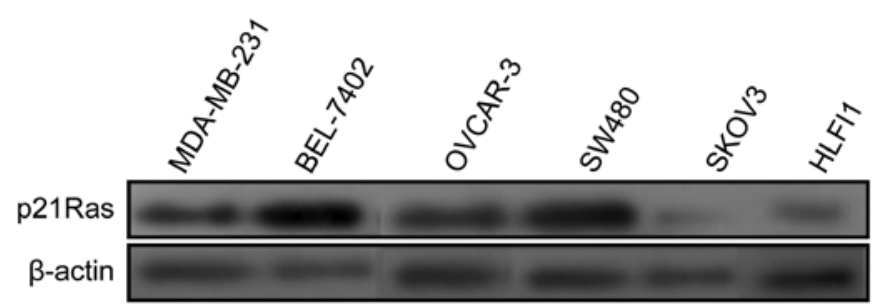

Figure 1. The expression of p21Ras protein in cell lines. The expression of p21Ras was analyzed by western blotting in tumor cell lines MDA-MB-231, BEL-7402, OVCAR-3, SW480 and human embryonic lung fibroblasts HLE-I. Proteins were detected by enhanced chemiluminescence with $\beta$-actin serving as a loading control.

tumor xenograft models were established by subcutaneous (s.c.) inoculation of $5 \times 10^{6}$ cells into the left subaxillary of 4-week-old female SPF BALB/c nude mice (Vital River Laboratory Animal Co. Ltd., Beijing, China), respectively. When tumors reached an average diameter of $0.5 \mathrm{~cm}$, mice were assigned randomly to treatment group (KGHV100) and control group (treated with Ad-hrGFP virus). Pre-established tumors were then injected with $3 \times 10^{8}$ plaque-forming units (pfu) of KGHV100 (with Ad-hrGFP virus as control) in $100 \mu 1$ solution. The injections were repeated seven times every three days. The conditions of each mouse was carefully observed every two days. Tumor growth was monitored by periodic measurements with calipers and tumor volume was calculated using the following formula: (maximal length) $\mathrm{x}$ (perpendicular width) ${ }^{2} / 2$. Tumor growth curve was draw using the data.

Mice were sacrificed at day 56 after injection, and the tumors were removed immediately and fixed in formalin, embedded in paraffin, sectioned at $4 \mu \mathrm{m}$ and stained with hematoxylin and eosin (H\&E). Immunohistochemically (IHC), sections were deparaffinized in xylene, hydrated in serial dilutions of ethanol and subsequently immersed in $1.5 \% \mathrm{H}_{2} \mathrm{O}_{2}$ to quench endogenous peroxidase activity. The sections were heated in citrate buffer $(10 \mathrm{mmol} / \mathrm{l}$ citric acid, $\mathrm{pH}$ 6.0) for antigen retrieval, then incubated with Ultra V Block (Thermo, USA) at room temperature for $30 \mathrm{~min}$. The sections were incubated with 1:400 diluted primary anti-Flag Tag rabbit polyclonal antibodies overnight at $4^{\circ} \mathrm{C}$. After three successive rinsing, the tissue sections were incubated with biotinylated goat anti-polyvalent plus for $30 \mathrm{~min}$ at room temperature. The slides were then washed and streptavidin peroxidase plus was added for $10 \mathrm{~min}$. After washing three times, the chromogen was developed for $5 \mathrm{~min}$ with liquid 3,3'-diaminobenzidine (Thermo). Finally, the slides were counterstained with hematoxylin, dehydrated and mounted with balsam for examination. Images were captured using the charge-coupled camera (Olympus, DP11) equipped with a microscope (Olympus, BX50), and processed using Adobe Photoshop software, version 5.0.

Measurement of tissue apoptosis. Tumor apoptosis was determined by terminal deoxynucleotidyl transferase-mediated dUTP-biotin nick end labeling (TUNEL) method according to the instructions of the manufacturer (In Situ Cell Death
Detection kit; Roche Diagnostics). The apoptotic indices were determined by counting the percentages of positive cells from five randomly selected high power fields.

Data analysis. Each result is expressed as the mean value \pm standard deviation of the mean. All statistical analyses were performed using SPSS Version 11.5. Student's t-test was applied for paired analyses to reveal statistical significance. Differences between multiple groups were analyzed by one-way analysis of variance (ANOVA). Survival rates were analyzed by the Kaplan-Meier method. Statistical significance is indicated by a P-value $<0.05$.

\section{Results}

Expression of p21Ras in tumor cell lines. Western blot analysis showed that $\mathrm{p} 21 \mathrm{Ras}$ protein displayed high expression level in SW480, MDA-MB-231, OVCAR-3, BEL-7402 cell lines, but the low level of $\mathrm{p} 21 \mathrm{Ras}$ expression was observed in SKOV3 cell line. In human lung fibroblast HFL1 cell line, p21Ras protein displayed a relatively basic expression level (Fig. 1).

Preparation of recombinant adenovirus KGHV100. We successfully constructed the recombinant adenovirus vector Ad-KGHR1-scFv (Fig. 2A) by subcloning anti-p21Ras scFv gene, KGHR1-scFv, into shuttle vector of replicationdefective adenovirus, in which the adenovirus E1 regions were deleted, and E3 gene was replaced by CMV promoter, Flag, IRES and hrGFP gene, then recombined with backbone vector pAdEasy-1in BJ5183-AD-1 cells. PCR amplification demonstrated the vector contained $\mathrm{scFv}$ gene (Fig. 2B). $P a c \mathrm{I}$ restriction showed different sized plasmid segments of 30 and $4.5 \mathrm{~kb}$ (homologous recombination occurred at the left and right arm) or 30 and $3 \mathrm{~kb}$ (homologous recombination occurred at replication starting section and the right arm) (Fig. 2C). By transfecting Ad-KGHR1-scFv and packaging in HEK293 cells we obtained the recombinant adenovirus KGHV100.

Intracellular expression of anti-p21Ras scFv fragments in tumor cells. Immunofluorescence studies revealed very distinct intracellular expression of anti-p21Ras scFv antibody in tumor cells infected with recombinant adenovirus KGHV100. Fig. 3 shows that KGHV100 was able to infect MDA-MB-231 cells and express reporter gene protein, green fluorescent proteins (GFP) and anti-p21Ras scFv antibody. The combination of the two fluorescence patterns is shown in Fig. 3C. The signal GFP (green) and the Flag signal (red) were combined and the two chromophores were superimposed in the same image with a green/red color scale, leading to yellow color in case of colocalization. The intracellular antibody displayed a cytoplasmic/perinuclear pattern.

KGHV100 inhibits the studied tumor cell lines in vitro. To validate the function of anti-p21Ras intracellular scFv antibody on tumor cell growth regulation, the tumor cell lines mentioned above were used in analysis in vitro. Colony formation assay indicated that colony-forming efficiency in BEL-7402 cells infected KGHV100 were decreased to $44.9 \%$, but in the 

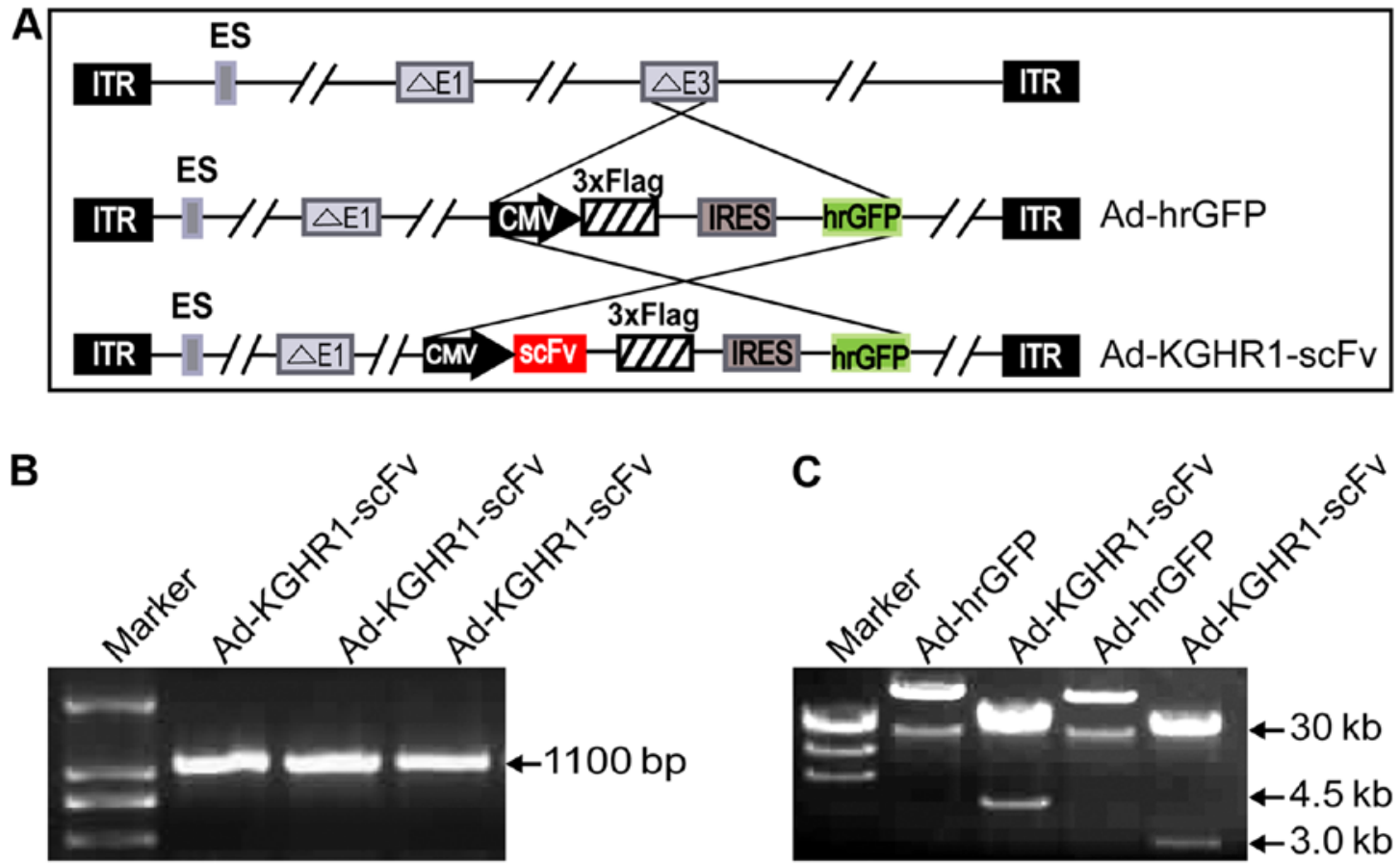

Figure 2. Construction and identification of recombinant adenovirus vector. (A) Structure of recombinant adenovirus vector Ad-KGHR1-scFv, single chain variable fragment (scFv) was inserted into the vector of Ad-hrGFP between the CMV promoter and the Flag Tags to obtain Ad-KGHR1-scFv. (B) Identification of the recombined adenovirus vector Ad-KGHR1-scFv by PCR. Target fragments (1,100-bp sized) which contain $750 \mathrm{bp}$ of scFv were derived from PCR amplification. (C) Segments 30- and 4.5-kb, 30- and 3-kb were obtained by PacI endonuclease restriction, which confirmed the correct recombination.
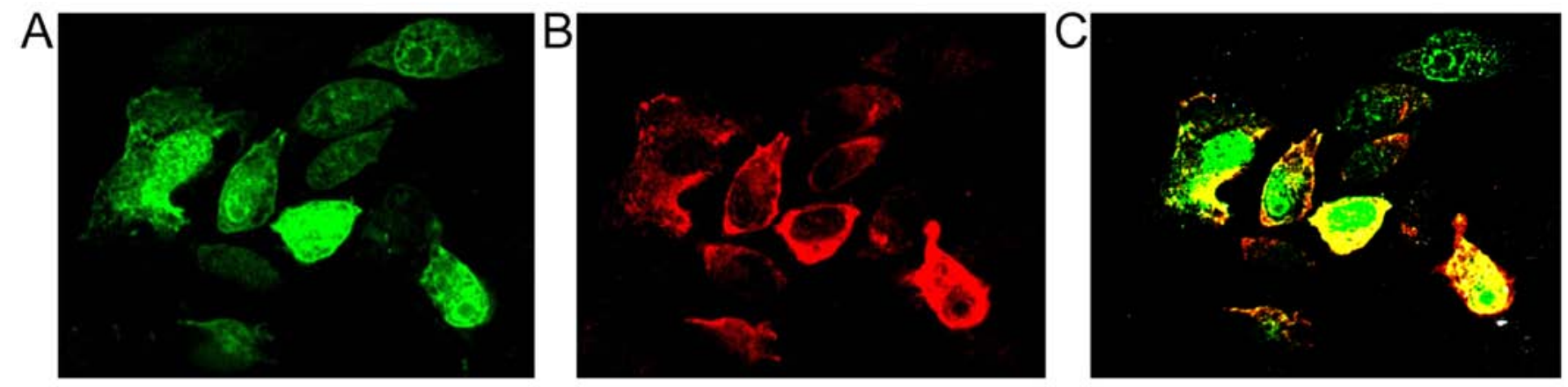

Figure 3. Intracellular expression of anti-p21Ras scFv in MDA-MB-231 cells by infection with KGHV100. (A) Confocal scanning showed green immunofluorescence signals of GFP reporter gene which represent KGHV100 in the cytoplasm. (B) Red immunofluorescence signals were found in the cytoplasm which represent the anti-p21Ras scFv antibody. (C) Merged image of the two fluorescence patterns (yellow) showed subcellular localization of the anti-p21Ras scFv antibody.

control groups (the cells were infected Ad-hrGFP) was 66.2\%, and the numbers of clones from tumor cells were reduced greatly after the infection with the KGHV100. Obviously, the difference of the two groups was statistically significant $(\mathrm{P}<0.05)$. Similar results were found in other tumor cell lines with high p21Ras expression. The colony-forming efficiency in MDA-MB-231, SW480 and OVCAR3 cells infected by KGHV100, respectively, was $21.7,25.0$ and $26.0 \%$, but in the control groups the colony-forming efficiency was 29.9 , 35.5 and $35.9 \%$, respectively. The clone formation capacity of tumor cell lines with high p21Ras expression was reduced by infection with KGHV100, the activities of cell replication were inhibited. However, the differences between the control and the experimental groups were not statistically significant in p21Ras lowly expressing SKOV3 cells (Fig. 4A).
Consistently, Transwell invasion assay showed that KGHV100 infection could significantly inhibit the invasive ability of the tumor cells of high p21Ras expression compared with Ad-hrGFP transfected groups. In contract, there was no apparent inhibition of invasive ability in SKOV3 cells of low p21Ras expression infected by either KGHV100 or Ad-hrGFP (Fig. 4B).

KGHV100 inhibits the tumor cell line viability and induces apoptosis in vitro. MTT assay was performed to detect cell viability after infection of KGHV100. As showed in Fig. 5A, there was no significant difference in proliferation between Ad-hrGFP and uninfected groups of the four lines studied. However, at 1, 2, 3, 4 and 5 days after KGHV100 infection, the cell proliferation of MDA-MB-231, BEL-7402 and SW480 

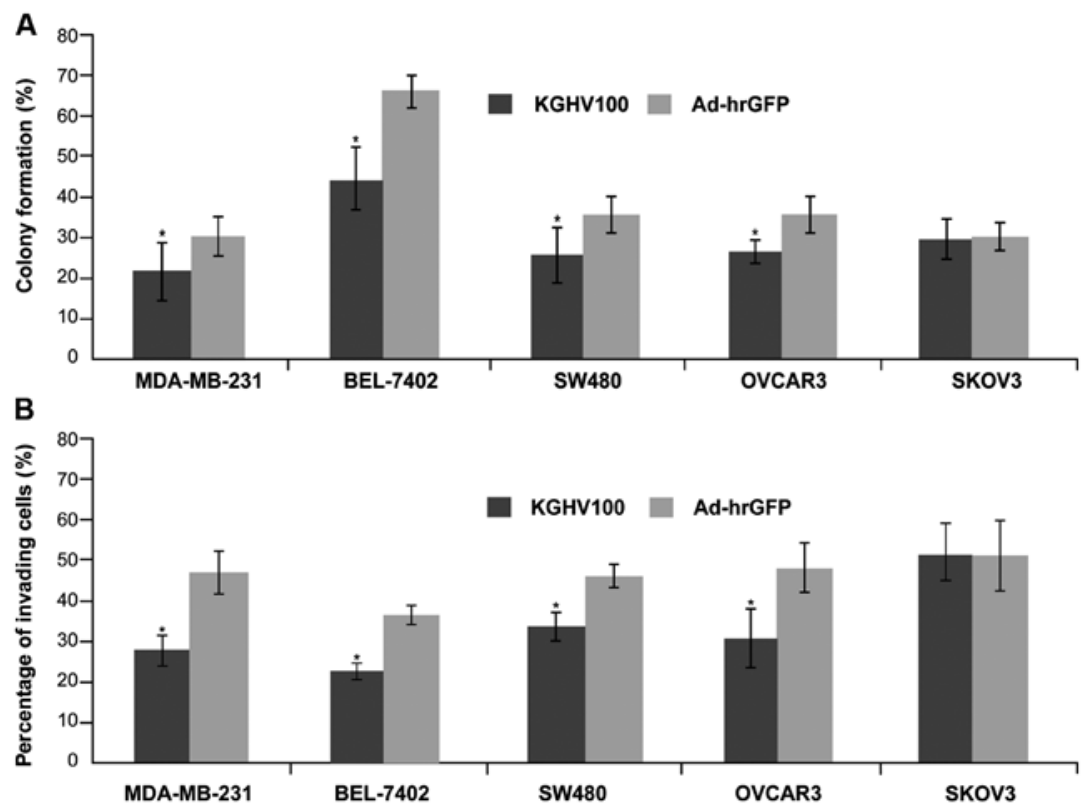

Figure 4. The growth inhibition of tumor cell lines by the recombinant adenovirus KGHV100 in vitro. (A) Colony formation assay indicated that the activities of cell replication were inhibited in tumor cell lines (MDA-MB-231, BEL-7402, SW480, and OVCAR3) with high p21Ras expression. (B) Matrigel-based Transwell assays were performed to determine the inhibition of invasiveness in vitro in the five tumor cell types. The invasive ability of the tumor cells of high p21Ras expression were significantly suppressed. All experiments were done in triplicate. Data are presented as mean $\pm \mathrm{SD}$. $\mathrm{P}<0.05$ Significantly different vs. Ad-hrGFP.
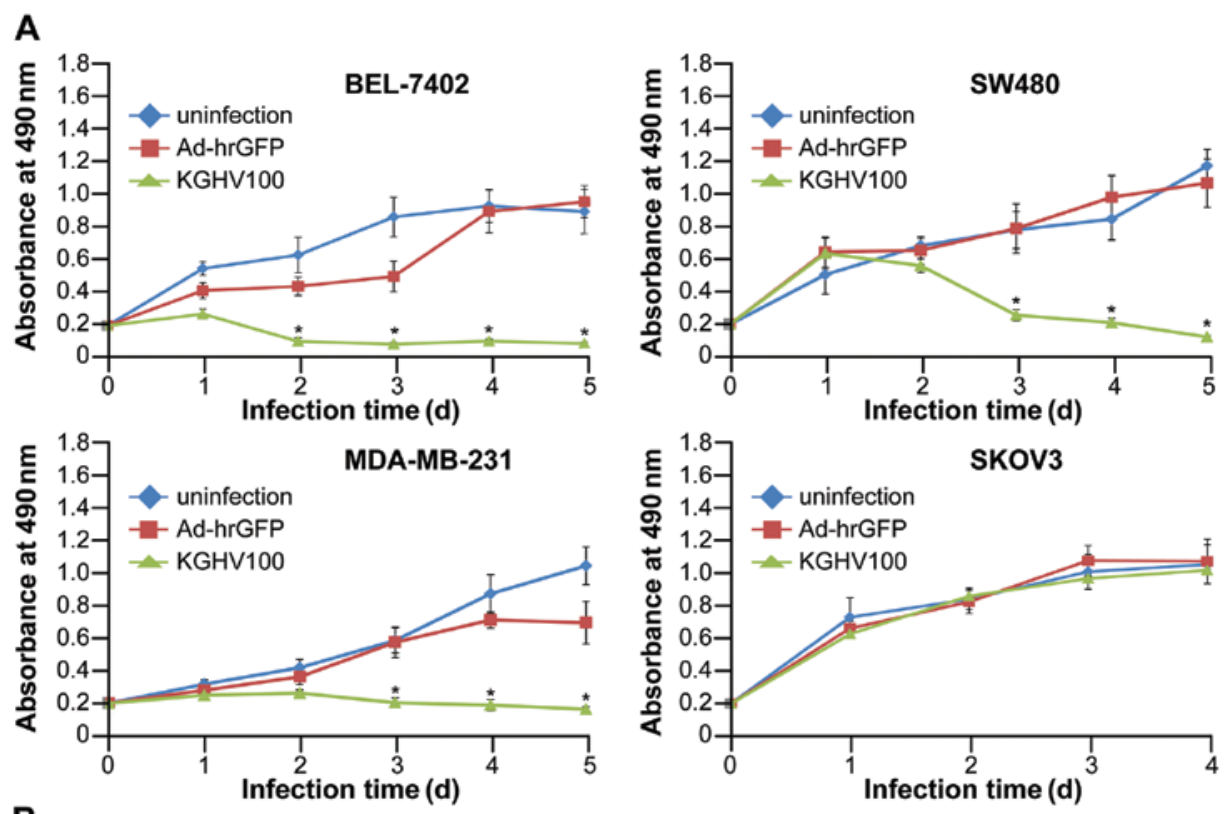

B

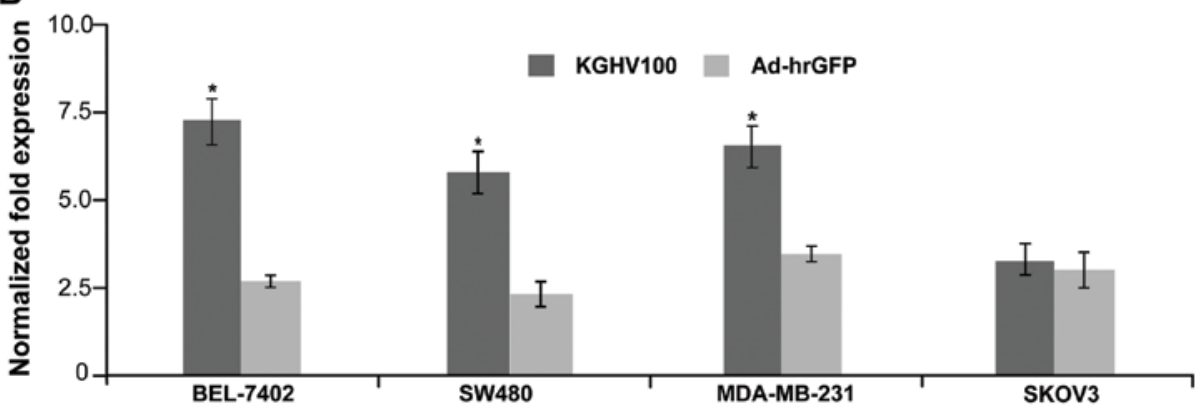

Figure 5. KGHV100 inhibits the tumor cell line viability and induces apoptosis in vitro. (A) MTT assay of cell growth in all four tumor cell lines treated with KGHV100 or the adenovirus of Ad-hrGFP at a MOI of 100. At 1, 2, 3, 4 and 5 days after treatment, MTT was added according to the manufacturer's protocol. Absorbance values were measured at $490 \mathrm{~nm}$ with enzyme-linked immunity implement. The tumor growth of high p21Ras expression cell lines (MDA-MB-231, BEL-7402 and SW480) were inhibited by KGHV100 infection. (B) qRT-PCR analysis of caspase-3 expression. The expression of caspase-3 increased significantly in three tumor cell types after infecting with KGHV100. All experiments were done in triplicate. Data are presented as mean \pm SD. ${ }^{*} \mathrm{P}<0.05$. Significantly different vs. Ad-hrGFP. 

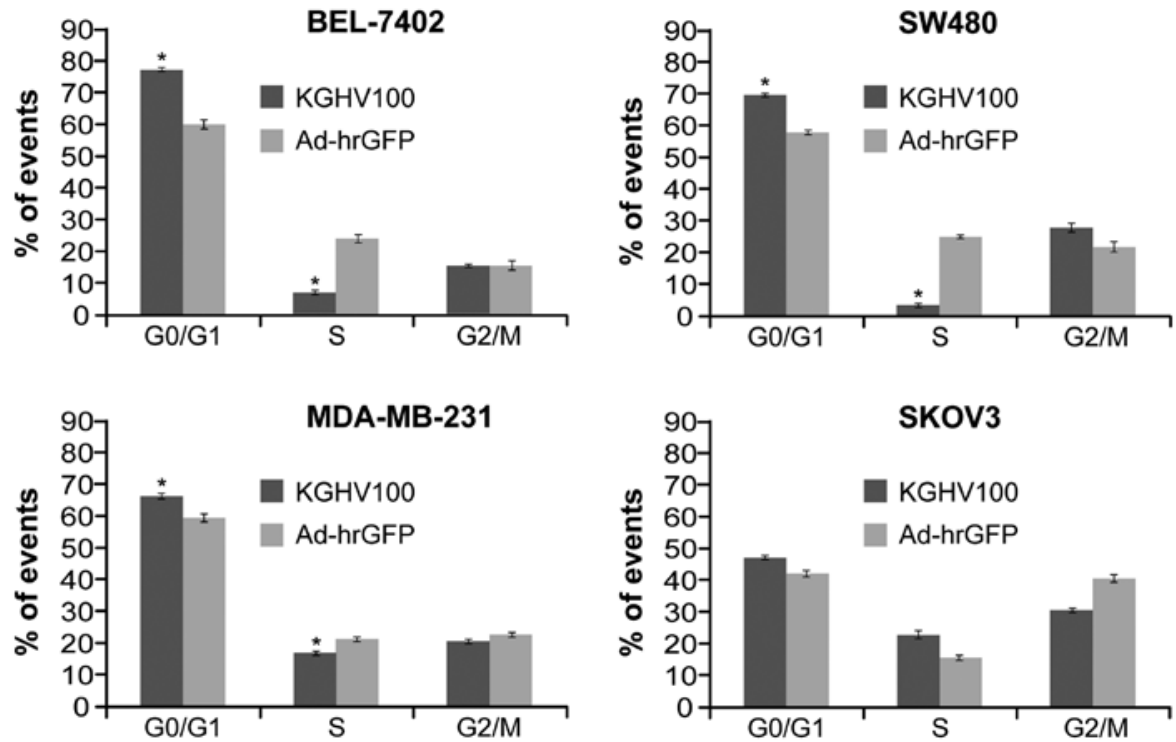

Figure 6. Impact of KGHV100 infection on the regulation of the cell cycle in tumor cell lines by FACS analysis. A significant increase in the percentage of G0/G1 phase cells and an obvious decrease in S phase cells were found in KGHV100 groups of high p21Ras expression (BEL-7402, SW480 and MDAMB-231). However, there was no significant difference in SKOV3 cells. All experiments were completed in triplicate. Data represent mean \pm SD. ${ }^{*} \mathrm{P}<0.05$. Significantly different vs. Ad-hrGFP.

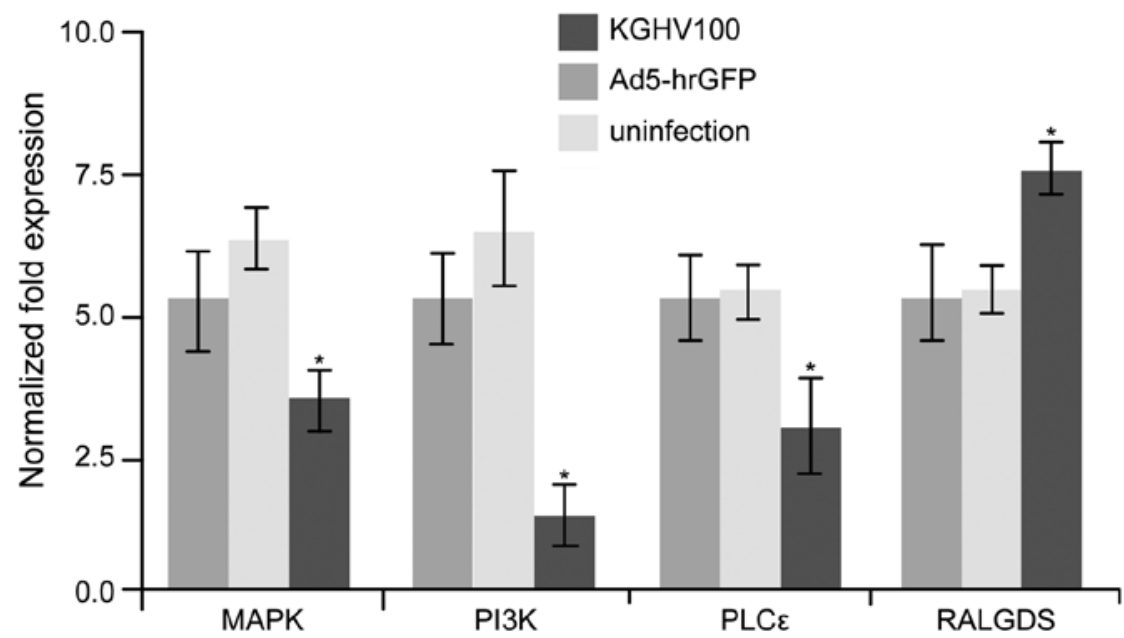

Figure 7. qRT-PCR analysis of the ras downstream gene expression. The expression of $M A P K 1, P I 3 K, P L C \varepsilon$ decreased significantly in tumor cells after infection by KGHV100. The expression of RALGDS gene increased in the KGHV100 group.

was significantly suppressed. Interestingly, a similar inhibitory effect was not observed in SKOV3 cells with low p21Ras expression. These results indicated that the growth of tumor cells with high p21Ras expression was inhibited by KGHV100 infection.

The expression of apoptosis-related gene caspase- 3 increased significantly in MDA-MB-231, BEL-7402 and SW480 in KGHV100 infected cells compared with the control groups. However, there was no significant difference in expressions of caspase-3 in the SKOV3 cell lines between KGHV100 and Ad-hrGFP groups (Fig 5B). This result showed that the KGHV100 was able to induce apoptosis in the three cell lines with high p21Ras expression.

The KGHV100 induces G0/G1 cell cycle arrest in the tumor cells. To examine the effect of KGHV100 on the cell cycle, flow cytometry was performed on the four tumor cell lines at $48 \mathrm{~h}$ after infection. The phase distribution of three lines infected with KGHV100 was markedly different from that of Ad-hrGFP groups. There was a significant increase in the percentage of G0/G1 phase cells and an obvious decrease in S phases cells in KGHV100 groups compared with Ad-hrGFP groups in the three cell lines with high $\mathrm{p} 21$ Ras expression $(\mathrm{P}<0.05)$. Whereas, there was no significant difference in SKOV3 cells with low p21Ras expression compared with control group $(\mathrm{P}>0.05)$ (Fig. 6). Thus, the KGHV100 could block cell cycle progression of the three tumor cell lines at G0/G1 phase.

KGHV100 inhibits the downstream gene expression of Ras. The expression of the ras downstream genes MAPK1, PI3K, PLCE and RALGDS in BEL-7402 cell line infected by KGHV100 was detected by qRT-PCR. As shown in Fig. 7, there were no 


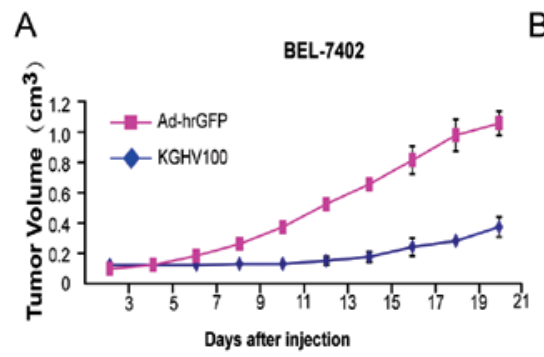

B
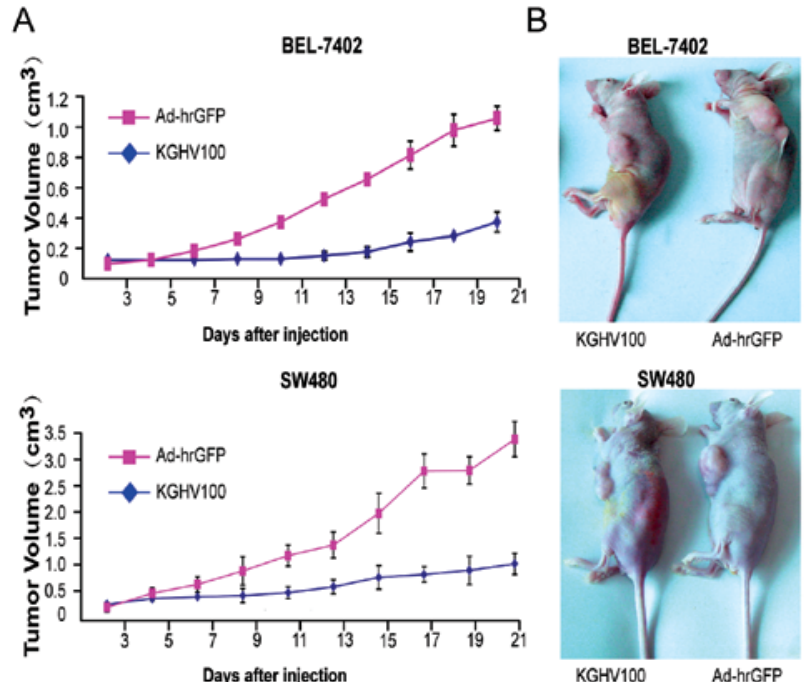

SKOV3

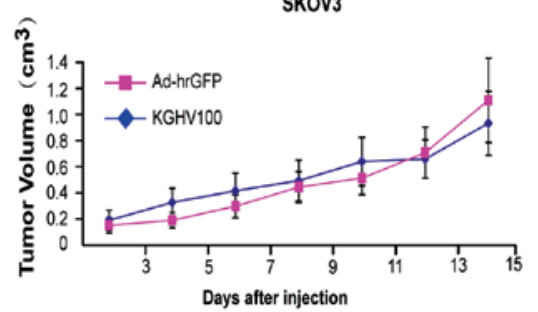

C

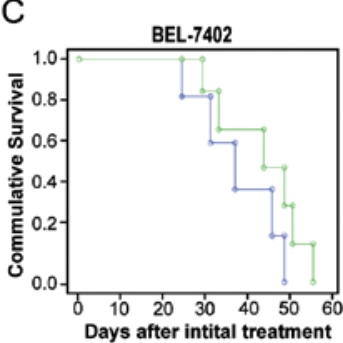

group

$\neg$ Ad-hrGFP

$\neg \mathrm{KGHV} 100$

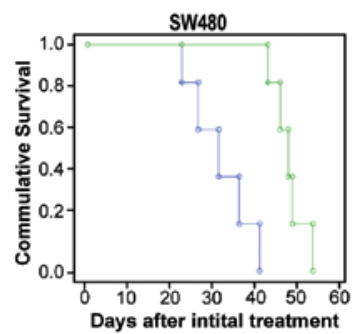

group

IAd-hrGFP

$\neg \mathrm{KGHV} 100$

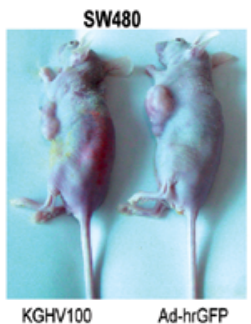

SKOV3
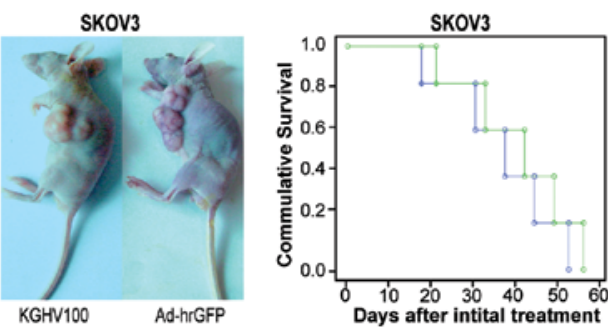

group

IAd-hrGFP

$\neg K G H V 100$

Figure 8. Tumor growth curve and Kaplan-Meier survival curve of xenograft models in Balb/c nude mice. (A) Tumor-bearing nude mice were injected with KGHV100 or the adenovirus of Ad-hrGFP every three days, seven times. The tumors grew remarkably slower and displayed a significant growth retardation in both two models of BEL-7402 and SW480 treated with KGHV100. (B) The images show xenograft tumors in nude mice at the end of the experiment. (C) Kaplan-Meier survival curve of xenograft models in Balb/c nude mice. There was a higher survival rate in the high p21Ras expression tumor mouse groups injected by KGHV100 than in control groups. Data represent mean \pm SD. ${ }^{*} \mathrm{P}<0.05$. Significantly different vs. Ad-hrGFP.

$\mathrm{HE}$
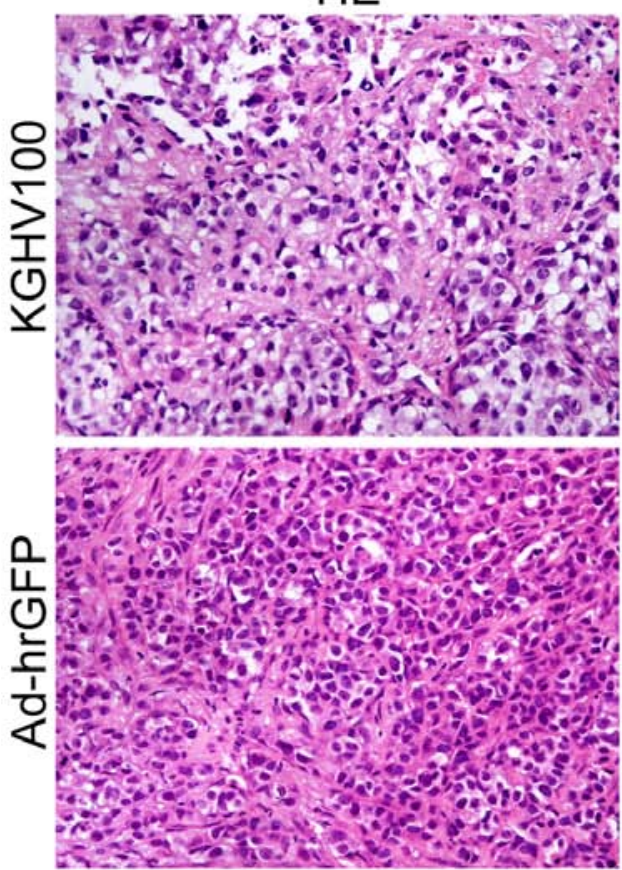

$\mathrm{IHC}$
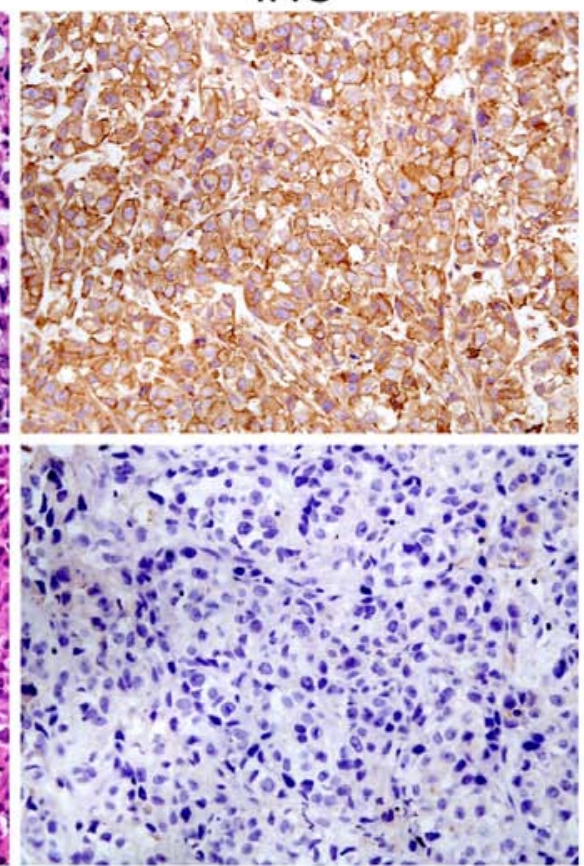

TUNEL
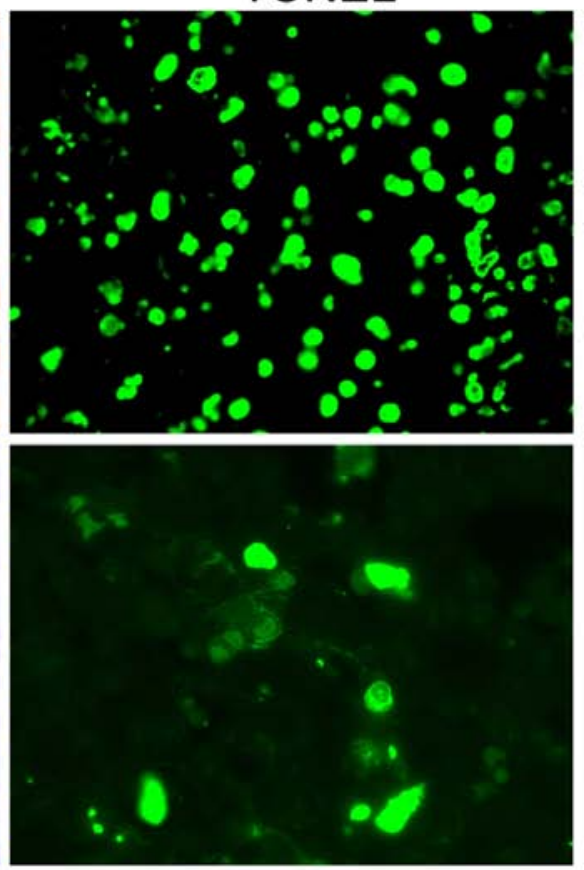

Figure 9. Histological and TUNEL staining for xenograft tumor tissues of nude mice. Hematoxylin and eosin (H\&E) showed that there were nuclear condensation, shrinkage of nuclear membrane and less mitotic tumors treated with KGHV100. However, the nuclear membrane was smooth, the nucleolis were prominent and there were more mitosis in tumors treated with Ad-hrGFP adenovirus (magnification, x400). Immunohistochemical staining (IHC) analysis showed high level of anti-p21Ras scFv expression in the xenograft tumors treated with KGHV100, but no anti-p21Ras scFv immunostain was found in the control group (magnification, $\mathrm{x} 400$ ). Apoptotic tumor cells were detected by TUNEL staining in the KGHV100 group (magnification, $\mathrm{x} 1,000$ ), whereas only a few apoptotic cells were found in the control group (magnification, $\mathrm{x} 1,000$ ). 
significant difference in expression of MAPK1, PI3K, PLCE and $R A L G D S$ in the Ad-hrGFP and the non-infected groups. However, the expression of $M A P K 1, P I 3 K$ and $P L C \varepsilon$ decreased significantly in tumor cells after infection with KGHV100. The expression of RALGDS gene increased in KGHV100 group compared to the control. Obviously, KGHV100 could inhibit the expression of the downstream genes of ras (Fig. 7).

KGHV100 slows down the growth of tumor xenografts in nude mice and induces apoptosis. To further investigate the therapeutic efficacy of KGHV100 in vivo, three kinds of tumor xenograft nude mouse models were, respectively, established by subcutaneously injecting BEL-7402, SW480 or SKOV3 cells. In the two models of BEL-7402 and SW480 treated with KGHV100, the tumors grew remarkably slower and displayed a significant growth retardation compared with those in Ad-hrGFP-treated mice $(\mathrm{P}<0.05)$. However, SKOV3-derived tumors displayed a significant growth regardless of injection by KGHV100 or Ad-hrGFP (Fig. 8A and B). This means that KGHV100 was capable of inhibiting tumor growth in p21Ras high expression tumor model. Kaplan-Meier analysis showed that high p21Ras expression tumor mice (BEL-7402, SW480) had higher survival rates in KGHV100 injected groups than in the control groups. However, in low p21Ras expression tumor mice (SKOV3) the survival rate showed no difference between the experimental and control groups (Fig. 8C).

Model mice were sacrificed at day 56 after injection, xenograft tumors were subjected to histopathological examination. Extensive central necrosis, which indicated that the tumors grew more quickly were observed in the tumor tissues from the control group of xenograft mice, whereas the feature was not displayed in the KGHV100 treated group (Fig. 9). IHC analysis demonstrated the cytoplasmic/perinuclear expression of the $\mathrm{scFv}$ in the xenograft tumors treated with KGHV100, but no $\mathrm{scFv}$ immune stain was found in the control group (Fig. 9).

More apoptosis of tumor cells were displayed in KGHV100 treated groups than in the control group. In the virus-treated groups, there were more obvious amounts of cancer cells positive for TUNEL stainning. The apoptosis index was $54.2 \pm 8.2$ in KGHV100 group, and $16.4 \pm 4.3$ in the control group (Fig. 9).

\section{Discussion}

The $\mathrm{scFv}$ antibody is an antigen-binding protein that consists of the $\mathrm{VH}$ and $\mathrm{VL}$ regions of the variable antigen-binding sites of immunoglobulin, connected by a short linker sequence (30). The scFv are generally of low molecular weights that improve their penetrability into cell membrane (31), but do not remain in cytoplasm for a long time. Intracellular antibody technology provides a key method to solve this problem $(32,33)$. The intracellular antibody can neutralize intracellular antigens by the ectopic expression of recombinant antibodies targeted to different intracellular compartments (33). Intracellular antibodies are synthesized inside of the cells by expressing vector such as adenovirus, adeno-associated virus, herpes simplex virus, retrovirus vector which carried the antibody gene (34). After the initial formal proof of intracellular antibody expression and targeting within the cell in 1990 (32), the function of many antigens has been successfully inhibited by intracellular expressing antibodies in the cytoplasm or the nucleus $(10,11,35,36)$, and it has been prospected as tools for gene therapy (37) and functional genomics study (38). Most present studies on cancer therapy with intracellular antibodies are focused on neutralizing certain proteins by intracellular scFv antibodies $(39,40)$. For example, recombinant adenovirus vector carrying anti erbB2-scFv gene was used for ovarian cancer therapy, which significantly prolonged the survival of tumor-bearing animals (12).

Ras is a well-known important oncogene involved in the development and progression of many human tumors, but no antibody drugs targeting ras have been approved for clinical application up to now. In a previous study (data not shown) we constructed anti-p21Ras scFv gene and prepared antip21Ras scFv antibody, KGH-R1, which was able to react with wild-type and mutation H-p21Ras, N-p21Ras and K-p21Ras proteins. To our knowledge, this is the first time using wildtype p21Ras as immunogens to prepare scFv antibody. In the present study we described a novel recombinant adenovirus KGHV100 by subcloning KGH-R1-scFv gene in a replicationdefective adenovirus vector and packaging in HEK293 cells.

Fluorescence microscopy demonstrated that KGHV100 expressed anti-p21Ras intracellular scFv antibody in both the cultured tumor cells and in transplantation tumors. MTT, Transwell and colony formation analysis showed that KGHV100 caused significant growth arrest in p21Ras high expressing tumor cells MDA-MB-231, BEL-7402, and SW480 in vitro. Furthermore, flow cytometry demonstrated KGHV100 can induce G0/G1 cell cycle arrest in the studied tumor cell lines. However, the growth, proliferation, invasion ability of the tumor cell line SKOV3 with low p21Ras expression were not suppressed by KGHV100 compared with the high p21Ras expression cell lines. qRT-PCR showed that KGHV100 inhibits the expression of ras downstream genes, MAPK1, $P I 3 K$ and $P L C \varepsilon$. Another downstream gene, the RALGDS, was slightly upregulated for, as yet, unclear reasons.

In vivo assays, we evaluated the antitumor effect of KGHV100 and observed notable growth inhibitory effects. Tumor cell lines with high p21Ras expression BEL-7402 and SW480 were selected to test the inhibition effects of the intrcellular scFv antibody on tumor growth by injecting the recombinant adenovirus KGHV100 into xenograft tumor established in Balb/c nude mice through tumor cell line transferation. It showed that the growth of tumors were significantly slower and the survival rates were longer in experimental group than in the control group. The intracellular antibody decreases tumor cell viability and invasion ability and inhibits tumor growth significantly. In SKOV3 (low p21Ras expression) mouse model, the tumor growth and survival rate of nude mice were not be affected by KGHV100. These results indicate that the adenovirus-mediated intracellular expression of anti-p21Ras scFv exerted strong antitumor activity, implied that it may be potentially used in gene therapy for cancers of p21Ras overexpression.

Conditionally replicating adenovirus (oncolytic adenovirus) is currently the best vector to carry therapy gene. However, it can proliferate and kill tumor cells, which make it difficult to differentiate antitumor effects between therapy gene and the adenovirus. The purpose of this study was to 
investigate whether our anti-p21Ras scFv could express within tumor cells and inhibit human ras-driven cancer cell growth. So we employed replication-defective adenovirus to carry the scFv gene instead of conditionally replicating adenovirus. In future, we will use conditionally replicating adenoviruses, the Ela and Elb genes controlled by the human telomerase reverse transcriptase (hTERT) promoter and the hypoxia response element (HRE), respectively, to increase the antitumor efficacy of this novel anti-p21Ras scFv.

\section{Acknowledgements}

This study was supported by the grants of National Natural Science Foundation of China (no. 30872994), the Scientific and Technological Key Project of Yunnan Province (no. 2006SG11), and the Applied Foundation Key Project of Yunnan Province (2013FA059).

\section{References}

1. Jemal A, Bray F, Center MM, Ferlay J, Ward E and Forman D: Global cancer statistics. CA Cancer J Clin 61: 69-90, 2011.

2. Fernández-Medarde A and Santos E: Ras in cancer and developmental diseases. Genes Cancer 2: 344-358, 2011.

3. Reddy EP, Reynolds RK, Santos E and Barbacid M: A point mutation is responsible for the acquisition of transforming properties by the T24 human bladder carcinoma oncogene. Nature 300: 149-152, 1982.

4. Adjei AA: Blocking oncogenic Ras signaling for cancer therapy. J Natl Cancer Inst 93: 1062-1074, 2001.

5. Downward J: Targeting RAS signalling pathways in cancer therapy. Nat Rev Cancer 3: 11-22, 2003.

6. Cochet O, Kenigsberg M, Delumeau I, Virone-Oddos A, Multon MC, Fridman WH, Schweighoffer F, Teillaud JL and Tocqué B: Intracellular expression of an antibody fragmentneutralizing p21 ras promotes tumor regression. Cancer Res 58: $1170-1176,1998$.

7. Prendergast GC, Davide JP, deSolms SJ, Giuliani EA, Graham SL, Gibbs JB, Oliff A and Kohl NE: Farnesyltransferase inhibition causes morphological reversion of ras-transformed cells by a complex mechanism that involves regulation of the actin cytoskeleton. Mol Cell Biol 14: 4193-4202, 1994.

8. Kohl NE, Omer CA, Conner MW, Anthony NJ, Davide JP, deSolms SJ, Giuliani EA, Gomez RP, Graham SL, Hamilton K, et al: Inhibition of farnesyltransferase induces regression of mammary and salivary carcinomas in ras transgenic mice. Nat Med 1: 792-797, 1995.

9. Canevari S, Biocca S and Figini M: Re: Blocking oncogenic Ras signaling for cancer therapy. J Natl Cancer Inst 94: 1031-1032, author reply 1032, 2002.

10. Mhashilkar AM, Bagley J, Chen SY, Szilvay AM, Helland DG and Marasco WA: Inhibition of HIV-1 Tat-mediated LTR transactivation and HIV-1 infection by anti-Tat single chain intrabodies. EMBO J 14: 1542-1551, 1995.

11. Duan L, Bagasra O, Laughlin MA, Oakes JW and Pomerantz RJ: Potent inhibition of human immunodeficiency virus type 1 replication by an intracellular anti-Rev single-chain antibody. Proc Natl Acad Sci USA 91: 5075-5079, 1994.

12. Deshane J, Siegal GP, Alvarez RD, Wang MH, Feng M, Cabrera G, Liu T, Kay M and Curiel DT: Targeted tumor killing via an intracellular antibody against erbB-2. J Clin Invest 96 : 2980-2989, 1995.

13. Cochet O, Kenigsberg M, Delumeau I, Duchesne M, Schweighoffer F, Tocqué B and Teillaud JL: Intracellular expression and functional properties of an anti-p21Ras scFv derived from a rat hybridoma containing specific lambda and irrelevant kappa light chains. Mol Immunol 35: 1097-1110, 1998.

14. Lener M, Horn IR, Cardinale A, Messina S, Nielsen UB, Rybak SM, Hoogenboom HR, Cattaneo A and Biocca S: Diverting a protein from its cellular location by intracellular antibodies. Eur J Biochem 267: 1196-1205, 2000.

15. Gysin S, Salt M, Young A and McCormick F: Therapeutic strategies for targeting ras proteins. Genes Cancer 2: 359-372, 2011.
16. Russell JS, Lang FF, Huet T, Janicot M, Chada S, Wilson DR and Tofilon PJ: Radiosensitization of human tumor cell lines induced by the adenovirus-mediated expression of an anti-Ras single-chain antibody fragment. Cancer Res 59: 5239-5244, 1999.

17. Van Etten B, Van Tiel ST, Ambagtsheer G, Eggermont AM and Ten Hagen TL: Isolated limb perfusion based anti-p21 ras gene therapy in a rat rhabdomyosarcoma. Anticancer Res 24 : 2295-2301, 2004.

18. Saki M, Toulany M and Rodemann HP: Acquired resistance to cetuximab is associated with the overexpression of Ras family members and the loss of radiosensitization in head and neck cancer cells. Radiother Oncol 108: 473-478, 2013.

19. Thor A, Horan Hand P, Wunderlich D, Caruso A, Muraro R and Schlom J: Monoclonal antibodies define differential ras gene expression in malignant and benign colonic diseases. Nature 311: 562-565, 1984.

20. Wakita K, Ohyanagi H, Yamamoto K, Tokuhisa T and Saitoh Y: Overexpression of c-Ki-ras and c-fos in human pancreatic carcinomas. Int J Pancreatol 11: 43-47, 1992.

21. Hamdy S, Aprikian A, Begin L, Fair W and Bazinet M: Ras p21 overexpression is a late event in prostate-cancer. Int J Oncol 4: 627-631, 1994.

22. Murugan AK, Munirajan AK and Tsuchida N: Ras oncogenes in oral cancer: The past 20 years. Oral Oncol 48: 383-392, 2012.

23. Zheng ZY, Tian L, Bu W, Fan C, Gao X, Wang H, Liao YH, Li Y, Lewis MT, Edwards D, et al: Wild-Type N-Ras, Overexpressed in basal-like breast cancer, promotes tumor formation by inducing IL-8 Secretion via JAK2 activation. Cell Reports 12: 511-524, 2015.

24. Hand PH, Thor A, Wunderlich D, Muraro R, Caruso A and Schlom J: Monoclonal antibodies of predefined specificity detect activated ras gene expression in human mammary and colon carcinomas. Proc Natl Acad Sci USA 81: 5227-5231, 1984.

25. Gerosa MA, Talarico D, Fognani C, Raimondi E, Colombatti M, Tridente G, De Carli L and Della Valle G: Overexpression of $\mathrm{N}$-ras oncogene and epidermal growth factor receptor gene in human glioblastomas. J Natl Cancer Inst 81: 63-67, 1989.

26. Novara R, Coda R, Martone T and Vineis P: Exposure to aromatic amines and ras and c-erbB-2 overexpression in bladder cancer. J Occup Environ Med 38: 390-393, 1996.

27. Luo J, Deng ZL, Luo X, Tang N, Song WX, Chen J, Sharff KA, Luu HH, Haydon RC, Kinzler KW, et al: A protocol for rapid generation of recombinant adenoviruses using the AdEasy system. Nat Protoc 2: 1236-1247, 2007.

28. Pelletier AJ, Kunicki T and Quaranta V: Activation of the integrin alpha v beta 3 involves a discrete cation-binding site that regulates conformation. J Biol Chem 271: 1364-1370, 1996.

29. He XP, Su CQ, Wang XH, Pan X, Tu ZX, Gong YF, Gao J, Liao Z, Jin J, Wu HY, et al: E1B-55kD-deleted oncolytic adenovirus armed with canstatin gene yields an enhanced antitumor efficacy on pancreatic cancer. Cancer Lett 285: 89-98, 2009.

30. Kaku Y, Noguchi A, Okutani A, Inoue S, Tanabayashi K, Yamamoto Y, Hotta A, Suzuki M, Sugiura N and Yamada A: Altered specificity of single-chain antibody fragments bound to pandemic H1N1-2009 influenza virus after conversion of the phage-bound to the soluble form. BMC Res Notes 5: 483, 2012.

31. Liu D, Wang C, Li C, Zhang X, Zhang B, Mi Z, An X and Tong Y: Production and characterization of a humanized singlechain antibody against human integrin alphav beta3 protein. $\mathrm{J}$ Biol Chem 286: 24500-24507, 2011.

32. Biocca S, Neuberger MS and Cattaneo A: Expression and targeting of intracellular antibodies in mammalian cells. EMBO J 9: 101-108, 1990.

33. Cattaneo A and Biocca S: Intracellular Antibodies: Development and Applications. Springer-Verlag, Berlin, pp1-196, 1997.

34. Thomas SM and Grandis JR: The current state of head and neck cancer gene therapy. Hum Gene Ther 20: 1565-1575, 2009.

35. Biocca S, Pierandrei-Amaldi P and Cattaneo A: Intracellular expression of anti-p21ras single chain Fv fragments inhibits meiotic maturation of xenopus oocytes. Biochem Biophys Res Commun 197: 422-427, 1993.

36. Marasco WA, Haseltine WA and Chen SY: Design, intracellular expression, and activity of a human anti-human immunodeficiency virus type 1 gp120 single-chain antibody. Proc Natl Acad Sci USA 90: 7889-7893, 1993. 
37. Rondon IJ and Marasco WA: Intracellular antibodies (intrabodies) for gene therapy of infectious diseases. Annu Rev Microbiol 51: 257-283, 1997.

38. Visintin M, Tse E, Axelson H, Rabbitts TH and Cattaneo A: Selection of antibodies for intracellular function using a twohybrid in vivo system. Proc Natl Acad Sci USA 96: 11723-11728, 1999.

39. Wang W, Sima N, Kong D, Luo A, Gao Q, Liao S, Li W, Han L, Wang J, Wang S, et al: Selective targeting of HPV-16 E6/E7 in cervical cancer cells with a potent oncolytic adenovirus and its enhanced effect with radiotherapy in vitro and vivo. Cancer Lett 291: 67-75, 2010.
40. Chang Y, Li Y, Hu J, Guo J, Xu D, Xie H, Lv X, Shi T and Chen Y: Adenovirus vector-mediated expression of TMEM166 inhibits human cancer cell growth by autophagy and apoptosis in vitro and in vivo. Cancer Lett 328: 126-134, 2013. 